\title{
POR UMA ESCOLA DEMOCRÁTICA: contribuições de Paulo Freire
}

\author{
Maria de Lourdes Teixeira Barros \\ Maria Inês Marcondes de Souza
}

Resumo

Paulo Freire, um pensador que construiu um projeto de educação emancipatória contra a opressão e a favor da liberdade, vem sendo justamente homenageado neste centenário de seu nascimento com muitas reflexões acerca de sua obra e das inúmeras contribuições para a educação, no Brasil e no mundo. Este ensaio tem por objetivo tratar dessas contribuições, em especial quanto às políticas públicas inovadoras que foram concretizadas quando de sua experiência como Secretário de Educação na cidade de São Paulo. A partir de uma revisão bibliográfica e documental, foi possível estabelecer um diálogo com suas políticas educacionais e compreender princípios fundamentais para a construção de uma escola verdadeiramente democrática, quais sejam: participação, descentralização e autonomia. Seja para a ação pedagógica em sala de aula ou para a gestão educacional, Freire contempla tais princípios em sua práxis e deixa um legado essencial para os educadores comprometidos com a justiça social.

Palavras-chave: Paulo Freire; educação democrática; políticas educacionais.

FOR A DEMOCRATIC SCHOOL: contributions by Paulo Freire

\begin{abstract}
Paulo Freire, the brazilian thinker who built an emancipatory education project against oppression and in favor of freedom, has been justly honored in this centenary of his birth with many reflections on his work and the numerous contributions that he left to education, not only in Brazil but all over the world. This essay aims to address these contributions, especially to innovative public policies that were implemented during his experience as Secretary of Education in the city of São Paulo. From a bibliographical and documentary review, it was possible to establish a dialogue with their educational policies and understand their fundamental principles for constructing a truly democratic school, namely: participation, decentralization and autonomy. Whether for pedagogical action in the classroom or for educational management, Freire included these principles in his practices and left an essential legacy for today's educators committed to social justice.
\end{abstract}

Keywords: Paulo Freire; democratic education; educational policies.

\section{PARA UNA ESCUELA DEMOCRÁTICA:}

\section{contribuciones de Paulo Freire}

Resumen

Paulo Freire, un pensador brasileño que construyó un proyecto de educación emancipadora contra la opresión y a favor de la libertad, ha sido justamente honrado en este centenario de su nacimiento con muchas reflexiones sobre su obra y las numerosas contribuciones que dejó a la educación en Brasil e en el mundo. Este ensayo tiene como objetivo abordar estos aportes, en particular a las políticas públicas innovadoras que se implementaron durante su experiencia como Secretario de Educación en la ciudad de São Paulo. A partir de una revisión bibliografía y documental, fue posible dialogar con sus políticas educativas y comprender los principios fundamentales para la construcción de una escuela verdaderamente democrática, 
a saber: participación, descentralización y autonomía. Ya sea para la acción pedagógica en el aula o para la gestión educativa, Freire incluye estos principios en su práctica y deja un legado esencial para los educadores comprometidos con la justicia social.

Palabras clave: Paulo Freire; educación democrática; políticas educativas.

\section{INTRODUÇÃO}

A escola cresceu muito em seus aparatos de fiscalização e controle e pouco em participação e democracia: cresceu no alto, mas não tem pés sólidos. Queremos inverter essa política, fortalecendo as bases da escola.

Paulo Freire ${ }^{1}$

A educação é um ato político e, como tal, deve possibilitar reflexões sobre os problemas que atingem a sociedade e, sobretudo, os grupos excluídos. Assim afirmou Paulo Freire em toda a sua obra, que se tornou guia e inspiração para educadores em todo o mundo. Em uma perspectiva de educação emancipatória, as classes populares foram alvo principal de sua proposta pedagógica. Com isso, construiu uma pedagogia que converge para a possibilidade de intervenção na realidade, no intuito de libertar aqueles que são oprimidos pelo sistema dominante.

Para Freire (1996), não existe neutralidade no ato de educar, pois as ações são pautadas a partir da definição de quem está sendo (ou não) favorecido com tais práticas. Característica marcante na pedagogia freireana, a humanização traz para a atividade docente afetividade, alegria e esperança. Assim, ele nos apresenta a compatibilidade de empreender uma educação com esses atributos a uma postura política e ao zelo quanto à cognoscibilidade do processo educativo (FREIRE, 1996). Não menos importante é a relação dialética teoria e prática, abordada por Freire quando propõe a ação docente crítica, em um movimento de reflexão permanente "entre o fazer e o pensar sobre o fazer" (FREIRE, 1996, p. 43), defendendo que, a partir dessa reflexão crítica, a prática pode mudar e tornar-se melhor.

Ao tratar de políticas educacionais, Freire propõe um modelo democrático, participativo, com autonomia e transparência. Este modelo foi levado a termo na sua administração na Secretaria Municipal de Educação de São Paulo (SME), servindo-nos como uma fonte de inspiração e aprendizado para compreendermos que é possível mudar a forma como fazemos política educacional. No entanto, este é um desafio para a escola como a temos hoje nas principais cidades do Brasil, em um contexto marcado por ampla diversidade cultural e social e permeado por diferentes interesses políticos e econômicos.

Neste ensaio, abordaremos aspectos da política desenvolvida por Freire, especialmente para a condução da gestão educacional, que se baliza pelos mesmos princípios de sua teoria para a prática pedagógica.

\section{POLÍTICAS EDUCACIONAIS PARA MUDAR A ESCOLA}

Ao assumir a SME, Freire compreendeu esse momento como uma forma de mudar a escola, a partir da sua realidade, para torná-la "uma escola bonita, voltada para a formação social crítica e para uma sociedade democrática" (SÃO PAULO, 1989, p.5). Para ele, esse era um projeto

\footnotetext{
1 Trecho do texto escrito por Freire e sua equipe do Gabinete da Secretaria de Educação da cidade de São Paulo, dirigido aos educadores da rede pública e publicado no Diário Oficial do Município de São Paulo, em 01 de fevereiro de 1989.
} 
coletivo para todos os envolvidos com a educação do município, sem imposição, com liberdade de expressão e de organização democrática. Seu objetivo era a formação de uma política educacional que garantisse a constituição de uma escola pública de qualidade, com ações de caráter "sistemático, gradual e permanente" (SÃO PAULO, 1989, p.6).

As políticas públicas empreendidas na Gestão Paulo Freire tiveram compromisso com a participação da comunidade escolar, a autonomia das instituições e a transparência nos processos da Secretaria de Educação. Dessa forma, objetivavam a construção de uma escola que levasse aos estudantes, professores e todos os demais atores educacionais o senso de pertencimento e o prazer de estar nela, e onde a quantidade de conteúdos não fosse o parâmetro para a medição de sua qualidade.

A valorização da participação coletiva pode ser verificada em diversos documentos da Secretaria, como no trecho a seguir:

Uma Escola Pública popular não é apenas aquela à qual todos têm acesso, mas aquela de cuja construção todos podem participar, aquela que atende realmente aos interesses populares que são os interesses da maioria; é, portanto, uma escola com uma nova qualidade baseada no compromisso, numa postura solidária, formando a consciência social e democrática (SÃO PAULO, 1989, p. 10).

Por participação entende-se que a decisão sobre os rumos da escola passa por toda a comunidade, incluindo estudantes e seus responsáveis. Consiste em levar a comunidade a participar da organização orçamentária e a discutir questões internas das unidades escolares, lhes oferecendo mais do que a oportunidade de trabalho voluntário na escola ou de contribuição financeira. Nessa perspectiva, a participação também se faz no processo de escolha do conteúdo programático, quando educador e educando se envolvem na seleção de temas que vão compor o currículo. A política educacional proposta por Freire indica que a construção curricular deve ser um processo dialógico entre educadores e comunidade escolar, com temas que surgirão da realidade e de interesses dessa comunidade.

Para a plena participação, os sujeitos precisam exercer sua autonomia nas instituições, com a descentralização de poder do Estado. Isso implica em compartilhar decisões e responsabilizações, trazendo para as esferas decisórias os profissionais diretamente envolvidos com os problemas cotidianos da comunidade escolar, por meio de representações em conselhos e afins. O gestor surge, nesse cenário, como um articulador entre as instâncias administrativas externas ao espaço escolar e à sua comunidade. Ao contrário, na maior parte das políticas públicas em curso no país, a descentralização surgiu como um processo para responsabilização e controle das escolas, incumbidas de executar tarefas pré-determinadas, sem participação efetiva nas decisões, restando ao Estado a sua função fiscalizadora. Para Freire (2001, p. 45), "estruturas administrativas a serviço do poder centralizado não favorecem procedimentos democráticos".

Entre os mecanismos criados para possibilitar que tal participação se efetivasse estavam a constituição de espaços de formação continuada e de planejamento das atividades docentes, o fornecimento de suporte para a aplicação das atividades planejadas coletivamente e a criação de fóruns com representação de todos os segmentos da comunidade escolar. O projeto, inovador, foi discutido com professores, estudantes, seus familiares e demais funcionários das instituições escolares. Freire percorreu pessoalmente as escolas, discutiu com sua equipe de trabalho e dialogou com as universidades para encontrar formas de suprir as deficiências encontradas, buscando avançar no processo de construção de uma escola pública democrática e de qualidade (FRANCO, 2014). 
Tal proposta, quando assim conduzida, permite que as instituições exerçam sua autonomia nas escolhas pedagógicas e na organização de suas ações.

O respeito à autonomia e à dignidade de cada um é um imperativo ético e não um favor que podemos ou não conceder uns aos outros (FREIRE, 1996, p. 66).

A autonomia institucional está ligada, de forma intrínseca, ao processo de descentralização empreendido. No entanto, isso não significa que o Estado esteja desobrigado de suas responsabilidades com a educação pública, devendo apoiar as escolas e suprir suas necessidades para viabilizar a execução das ações planejadas, impedindo também a precariedade do espaço físico.

\section{PRINCÍPIOS DEMOCRÁTICOS PARA A EDUCAÇÃO}

Compreendendo a escola pública como espaço de educação popular, Freire defende a democratização do acesso às escolas, o aumento de investimentos estatais na educação e a melhoria na qualidade do ensino. Para levar a cabo essa proposta de democratização, considerou como base a transparência das ações, com eficiência na divulgação de informações entre todos os atores educacionais e a manutenção de um canal aberto ao diálogo, além de buscar a "liberdade de expressão e de organização como elementos constitutivos essenciais da democracia e, consequentemente, de uma política educacional que vise à construção de uma escola pública de qualidade" (SÃO PAULO, 1989, p.6).

Ao assumir a administração da SME, uma das medidas iniciais adotadas foi mapear a situação do espaço físico das escolas da rede, em busca de realizar investimentos necessários para sua reforma e melhoria. O diagnóstico incluiu, além das questões da parte física, outros problemas a serem enfrentados: evasão (chamada por ele de expulsão), repetência, conservadorismo, impossibilidade de acesso a muitas crianças, apatia, desconfiança, medo, indiferença, processos pedagógicos inadequados (SÃO PAULO, 1989). Problemas esses ainda tão comuns no campo educacional, em diversas partes do Brasil. Para Freire, a solução partia de uma maior participação da comunidade escolar nas instâncias decisórias.

Segundo Torres et al (2002), sua administração definiu quatro linhas de ações em busca do objetivo de construir uma escola pública popular, de qualidade e democrática: inovações curriculares e valorização do magistério; criação de canais para comunicação e participação da comunidade escolar na tomada de decisões; apoio técnico e financeiro para a promoção do movimento de alfabetização de jovens e adultos; democratização do acesso, o que se deu com renovação e expansão de instituições já existentes e ampliação da rede.

No âmbito pedagógico, empreendeu ampla reforma curricular, a partir de estratégias que envolviam a participação dos profissionais das escolas junto à sua equipe. Dessa forma, colocou em ação a proposta de democratização, cujos princípios de participação, descentralização e autonomia estavam intrínsecos. A reforma incluiu novos processos para tomada de decisões ao criar coletivos nas bases - os Conselhos de Escola e os Núcleos de Ação Educativa (NAE). A estrutura, buscando romper com organizações hierárquicas, contava com um colegiado central formado pela equipe da SME, um colegiado intermediário - equipe central e representantes dos NAE e os colegiados locais - dos quais participavam o coordenador do NAE e sua equipe local. 
Esses colegiados debateram a reconstrução do Regimento Comum das Escolas ${ }^{2}$, propuseram o repasse de verbas do governo para a manutenção de prédios e equipamentos, estimularam a formação e fortalecimento de Grêmios Estudantis e a revisão dos papéis das associações de Pais e Mestres, que passariam a ter participação efetiva nos rumos do processo educacional. No caso dos grêmios, as escolas destinariam salas para que os grupos se organizassem (FRANCO, 2014).

A elaboração de novas propostas curriculares, a partir de reflexões sobre as práticas realizadas e de trocas de experiências entre as escolas, destacou-se como exemplo de um processo de construção curricular coletivo, dialógico e autônomo. Chamado "Movimento de Reorientação Curricular", esse processo contou com a participação de "diferentes grupos em constante diálogo: a escola, a comunidade e especialistas em diferentes áreas do conhecimento" (SAUL, 2012, p. 6).

A construção coletiva desse currículo foi pautada por várias linhas de ação, entre elas a da escuta e a da discussão da realidade das escolas, por meio de diálogo entre os segmentos, que depois eram transformadas em "cadernos" que retornavam para as escolas para fomentar a troca de experiências. As escolas receberam apoio técnico e financeiro da Secretaria para a construção de seus projetos político-pedagógicos (FRANCO, 2014, p. 114).

Tal lógica de construção curricular é a mesma defendida por Freire para a construção de conhecimento no trabalho pedagógico desenvolvido junto aos estudantes: uma educação dialógica, de participação coletiva e definida a partir da realidade e dos interesses dos grupos.

A organização do programa a ser desenvolvido nas escolas, decidido a partir do levantamento de temas geradores, identificados por alunos e professores, por meio de estudo da realidade local, exigiu a criação de uma nova arquitetura de trabalho na escola porque era necessário romper com a lógica instalada há 60 anos, nessa rede de ensino, que se caracterizava por propostas curriculares definidas "de cima para baixo", por instâncias superiores da Secretaria de Educação que geravam um trabalho individualizado, por parte dos professores, com intenção de depositar conhecimento nas supostas "cabeças vazias" dos alunos (SAUL, 2012, p. 7).

O fortalecimento da relação professor-aluno é um pilar para a educação democrática. Com esse pensamento, há de se valorizar os profissionais da educação, sua atuação e formação permanente, permitindo-os serem sujeitos da ação pedagógica. Igualmente, valorizar todos os alunos em suas especificidades: crianças, jovens ou adultos, trabalhadores ou não, do ensino diurno ou noturno. Freire argumenta a favor de um tratamento sério e sistemático a todos os níveis de ensino, cuja qualidade educacional não será medida pela quantidade de conteúdo, mas pela possibilidade dada pela escola a todo seu público, incluindo a comunidade externa, de "utilizá-la como um espaço para elaboração de sua cultura” (SÃO PAULO, 1989, p.8).

\footnotetext{
${ }^{2}$ Este já havia sido aprovado pelo Conselho Estadual de Educação (CEE), em 1985, prevendo a criação dos Conselhos de Escola. No entanto, ainda não entrara em vigor até então, o que foi feito imediatamente após a assunção de Paulo Freire ao cargo de Secretário de Educação.
} 
Participação, descentralização e autonomia

Colocados estes como três princípios básicos para nortear a proposta educacional democrática, Freire demonstra caminhos possíveis para fazê-la acontecer, ressaltando, porém, que não são caminhos fáceis, mas também não são impossíveis de se construir.

A escola pode superar seu isolamento da comunidade chamando-a à participação. Esta pode se dar com consulta à comunidade para o estabelecimento das ações educativas e com o atendimento aos interesses e à realidade local nos planejamentos pedagógicos. Os conselhos e/ou colegiados foram concebidos como instâncias de participação para que todos atuem nas decisões e para que as escolas exerçam sua autonomia. No documento inicial da SME sobre o projeto de reconstrução curricular, afirma-se que "tanto a participação, de educadores, educandos e comunidade, quanto a descentralização levam ao poder compartilhado" (SÃO PAULO, 1990a, p. 14).

$\mathrm{Na}$ administração de Paulo Freire, a estrutura estava organizada para possibilitar tal participação. Conforme já dito, foram criados os NAE, núcleos com especialistas das diferentes disciplinas e com dois técnicos responsáveis por cada escola, que ofereciam aos professores aconselhamento técnico e eventos formativos, como cursos, palestras, congressos e atividades culturais, em parceria com universidades. Inicialmente, foram realizados seminários na Universidade de São Paulo, que tiveram continuidade com a criação de Grupos de Formação Contínua. Esses grupos se estabeleceram como "oportunidades regulares de diálogo, de intercâmbio e de leitura para os professores, através da concessão de dez horas pagas por semana para reuniões nas escolas" (TORRES et al, 2002, p. 125). Os grupos de formação constituíam um exemplo do que se preconizava com a proposta educacional de Freire. Diferentemente dos cursos, representavam uma oportunidade para a troca entre os pares e para uma reflexão sobre a prática cotidiana, gerando amplo debate sobre as crenças e ideologias de cada profissional. Exigindo do educador um papel ativo, mostrou-se um caminho mais profícuo para a transformação da ação pedagógica e para o fortalecimento do senso de coletividade.

O educador deverá vivenciar no grupo o mesmo processo que queremos que propicie aos seus educandos. Educar-se numa concepção de mundo e de homem onde a relação ensinar-aprender se dá dinamicamente, onde a consciência é um processo contínuo, permanente, desafiador (SÃO PAULO, 1990b, p. 11).

Outro passo para atingir participação, descentralização e autonomia em sua gestão foi a realização de um "Projeto Interdisciplinar", também chamado de "Projeto Inter", com a finalidade de promover aperfeiçoamento curricular. Baseava-se em quatro princípios: construção coletiva; autonomia das escolas e valorização de suas experiências; ação-reflexão-ação no cotidiano escolar; formação contínua dos educadores (TORRRES et al, 2002). Segundo esse autor, o projeto Inter foi apresentado às escolas como uma opção para a ação pedagógica, porém, aquelas que não o quisessem poderiam desenvolver propostas independentes, em coerência com os princípios nos quais o projeto se referenciava.

\section{CONSIDERAÇÕES}

A proposta pedagógica de Freire tem uma clara definição política a favor dos oprimidos e por uma crítica às convicções neoliberais, constituídas de práticas perversas para os grupos sociais 
menos favorecidos. Estas promovem uma narrativa de realidade pronta, imutável e imperativa para a sociedade, buscando difundir tal ideologia via mídia e outros espaços de formação, como a escola.

Conforme afirma Freire (1996), a educação é política, seja no espaço da sala de aula ou nas instâncias administrativas. As escolhas de cada educador - currículo, metodologia, estratégias - são orientadas por suas concepções políticas e por sua crença no que seja a finalidade da educação. Não há neutralidade, visto que "já estamos mergulhados em um mundo desigual em que a educação exige um posicionamento a favor ou contra o status quo estabelecido" (ZITKOSKI, 2006, p. 52). Mesmo quando o educador tenta se eximir de um posicionamento, declarando-se neutro, está na verdade se posicionando a favor do discurso dominante e determinista neoliberal. Dessa forma, para que a educação seja uma prática democrática é preciso ter como perspectiva a necessidade de se buscar superar a reprodução das estruturas sociais que provocam tamanha desigualdade.

A educação emancipatória, em contraponto à educação bancária (FREIRE, 1987; 1992; 1996), requer uma ação política dos educadores, nos espaços micro e macro da formulação de políticas educacionais. As estruturas administrativas devem estar descentralizadas, a favor da autonomia das escolas e da participação efetiva da comunidade escolar para que se sustente uma prática democrática. Conselhos ou Colegiados escolares devem ser deliberativos, diminuindo o poder da Direção ou da Secretaria de Educação e ampliando a voz da Comunidade.

Assim como os professores devem partir da realidade dos educandos para a construção curricular, são as experiências das salas de aula que constituem a base para as políticas educacionais, devendo a administração central ter uma relação direta com as instituições escolares, funcionando não como agente fiscalizador, mas como estrutura de apoio às instituições.

Dividir o poder de pensar, elaborar e decidir requer sistematicamente a socialização de informações e a capacidade de conviver e experimentar as tensões e contradições inerentes à democracia. Isto só não acontece quando o autoritarismo impera e mata a riqueza e as dificuldades próprias de qualquer processo que tenha a participação como pressuposto (SÃO PAULO, 1992, p.1).

O legado de Paulo Freire nos mostra que é possível a democratização da educação em diferentes esferas, embora isso ainda represente um desafio para um Estado afeito a processos autoritários. Consideramos que a democratização das estruturas de poder só será feita com educadores que tenham compromisso político com a justiça social e que tenham clareza a favor de quem está a educação que praticam.

\section{REFERÊNCIAS}

FRANCO, Dalva de Souza. A gestão de Paulo Freire à frente da Secretaria Municipal de Educação de São Paulo (1989-1991) e suas consequências. Pro-posições, v.25, n.3 (75), p. 103-121, set./dez. 2014.

FREIRE, Paulo. Pedagogia do Oprimido. Rio de Janeiro: Paz e Terra, 1987.

FREIRE, Paulo. Pedagogia da Esperança: um reencontro com a pedagogia do oprimido. Rio de Janeiro: Paz e Terra, 1992. Notas: Ana Maria Araújo Freire.

FREIRE, Paulo. Pedagogia da Autonomia: saberes necessários à prática educativa. São Paulo: Paz e Terra, 22 ed., 1996.

FREIRE, Paulo. À Sombra desta mangueira. São Paulo: Editora Olho D’água, 2001. 
DOI: $10.12957 /$ teias.2021.62048

SÃO PAULO (Cidade). Secretaria Municipal de Educação. Aos que fazem a educação conosco em São Paulo: Construindo a Educação Pública Popular. Diário Oficial do Município de São Paulo, São Paulo, ano 34, n. 21, Suplemento, 01 fev. 1989. Disponível em: https://pt.scribd.com/doc/234568470/1989-Aos-que-fazem-a-educacao-conosco-em-SaoPaulo-Construindo-a-educacao-publica-popular-ano-1. Acesso em: 10 jul. 2021.

SÃO PAULO (Cidade). Secretaria Municipal de Educação de São Paulo. Cadernos de formação: um primeiro olhar sobre o projeto. São Paulo, 1990a.

SÃO PAULO (Cidade). Secretaria Municipal de Educação de São Paulo. Cadernos de formação: grupos de formação - uma (re) visão da educação do educador. São Paulo, 1990b.

SÃO PAULO (Cidade). Secretaria Municipal de Educação de São Paulo. Diário Oficial do Município de São Paulo, São Paulo, ano 37, n. 195, 15 out. 1992. Disponível em: http://www.docidadesp.imprensaoficial.com.br/NavegaEdicao.aspx?ClipId=6EN55PFM1KQ5 Ue39LLFNTQ510HU. Acesso em: 10 ago 2021.

SAUL, Ana Maria. A construção da escola pública, popular e democrática na gestão Paulo Freire, no município de São Paulo. In: TOMMASIELLO, Maria Guiomar Carneiro et al. (org.). Didática e práticas de ensino na realidade escolar contemporânea: constatações, análises e proposições. Araraquara: Junqueira \& Marin, 2012.

TORRES, Carlos Alberto; O'CADIZ, Maria del Pilar; WONG, Pia Lindquist. Educação e Democracia: a práxis de Paulo Freire em São Paulo. São Paulo: Cortez: Instituto Paulo Freire, 2002.

ZITKOSKI, Jaime José. Paulo Freire \& educaşão. Belo Horizonte: Autêntica, 2006.

\section{Informações das autoras}

Maria de Lourdes Teixeira Barros

Pontifícia Universidade Católica do Rio de Janeiro - PUC-Rio

Professora Titular aposentada do Colégio Pedro II

E-mail: lourdestbarros@gmail.com

ORCID: https://orcid.org/0000-0003-1593-7018

Link Lattes: http://lattes.cnpq.br/8254767650606079

Maria Inês Marcondes de Souza

Pontifícia Universidade Católica do Rio de Janeiro - PUC-Rio

Professora Departamento de Educação

E-mail:mim@puc-rio.br

ORCID: https://orcid.org/0000-0002-0973-9405

Link Lattes: http://lattes.cnpq.br/9002784880708799 